\title{
Resection of colorectal liver metastases following neoadjuvant chemotherapy
}

\author{
A Chiappa ${ }^{1}$, E Bertani ${ }^{1}$, R Biffi ${ }^{2}$, U Pace ${ }^{1}$, G Viale $^{3}$, G Pruneri ${ }^{3}$, G Zampino ${ }^{4}$, N Fazio ${ }^{4}$, F Orsi $^{5}$, G Bonomo ${ }^{5}$, L Monfardini ${ }^{5}$, P Della \\ Vigna $^{5}$ and $B$ Andreoni ${ }^{1}$
}

${ }^{1}$ Department of General Surgery-Laparoscopic Surgery, European Institute of Oncology, University of Milano, 20141, Italy

${ }^{2}$ Division of Abdomino-pelvic Surgery, European Institute of Oncology, University of Milano, 20141, Italy

${ }^{3}$ Department of Pathology, European Institute of Oncology, University of Milano, 20141, Italy

${ }^{4}$ Department of Oncology, European Institute of Oncology, University of Milano, 20141, Italy

${ }^{5}$ Department of Radiology, European Institute of Oncology, University of Milano, 20141, Italy.

Antonio Chiappa: assisted in the format and design of the paper

Bruno Andreoni, Roberto Biffi: critical review

Emilio Bertani, and Vincenzo Bagnardi: statistical analysis and performed the literature search

Ugo Pace, Emilio Bertani: managed the patients and performed the literature search

Giuseppe Viale, and Giancarlo Pruneri: histopathology evaluation

Giulia Zampino, Nicola Fazio: oncologists

Franco Orsi, Guido Bonomo, Lorenzo Monfardini, Paolo Della Vigna: radiologists

\section{Abstract}

Background/aims: Hepatic resection in metastatic disease from colorectal cancer offers the best chance in selected cases for long-term survival. Neoadjuvant chemotherapy (NACT) has been advocated in some cases initially deemed irresectable, with few reports of the efficacy of such a strategy and the influence of the response to chemotherapy on the outcome of radical hepatic resection.

Methodology: Between December 1995 and May 2005, 27 patients with colorectal liver metastases (seven males, 20 females, mean age: $58 \pm 8$ years; range: 40-75) were treated with neoadjuvant chemotherapy. A seven-year survival analysis was performed. Chemotherapy included mainly 5-fluorouracil, leucovorin and either oxaliplatin or irinotecan for a median of eight courses.

Results: A total of 16 patients (59\%) had synchronous and $11(41 \%)$ metachronous metastases. During pre-operative chemotherapy, tumour regression occurred in ten cases (37\%), stable disease in a further ten patients $(37 \%)$ and progressive disease developed in seven cases (26\%). The five-year overall survival for NACT responders was $64 \%$ and only $15 \%$ for non-responders $(p=0.044)$.

Conclusions: The response to chemotherapy is likely to be a significant prognostic factor affecting survival after liver resection for cure.

Abbreviations used in the text: NACT: neoadjuvant chemotherapy; SD: stable disease; CT scan: computed tomography; MRI: magnetic resonance imaging; IOUS: intra-operative ultrasonography; CUSA: ultrasonic dissector-harmonic scalpel; TARF: radiofrequency ablation device; CVC: central venous catheter

Published: 16/10/2007

Received: $20 / 08 / 2007$

ecancer 2007, 1:58 DOI: 10.3332/ecancer.2008.58

Copyright: (c) the authors; licensee ecancermedicalscience. This is an Open Access article distributed under the terms of the Creative Commons Attribution License (http://creativecommons.org/licenses/by/2.0), which permits unrestricted use, distribution, and reproduction in any medium, provided the original work is properly cited.

Competing Interests: The authors have declared that no competing interests exist.

Correspondence to A Chiappa. Email: antonio.chiappa@ieo.it 


\section{Introduction}

Surgical resection of colorectal liver metastases, where possible, still remains the only treatment ensuring long-term survival, when margin-free (R0) hepatic resection can result in $25-35 \%$ reported overall five-year survival [1-7]. This contrasts with the dismal long-term prognosis either of untreated hepatic metastases [8] or even that where conventional chemotherapy alone is used [9-11]. Controversy still remains concerning the timing of hepatectomy in resectable cases, either as a stage delayed or as a synchronous resection [12,13] as well as the neoadjuvant usage of chemotherapy prior to hepatic resection particularly if the disease is initially assessed as irresectable $[14,15]$.

The perioperative risks of liver resection have been substantially reduced in recent years. It is not, however, clear whether systemic pre-operative chemotherapy increases the morbidity of subsequent surgery through the induction of steatosis, sinusoidal congestion and centrilobular necrosis as has been reported with fluoropyrimidine analogues $[16,17]$ or as a result of an increased risk of bleeding during surgery where the postchemotherapy hepatic parenchyma tends to be more congested and friable following intra-arterial therapy [18]. The effects of systemic chemotherapy on the liver parenchyma and on the post-operative course following resection have been relatively poorly assessed in groups of patients where there has been considerable heterogeneity of chemotherapeutic agents utilized and variation in the types and techniques of liver resections performed [19-22]. The present study reports the effects and outcome of pre-operative systemic chemotherapy use in a consecutive series of 27 patients presenting with colorectal liver metastases as an aid and a guide to definitive metastasis resection with curative intent.

\section{Methodology}

Between April 1996 and February 2005, 27 consecutive patients affected by colorectal liver metastases received systemic chemotherapy prior to liver surgery (seven males; 20 females; mean overall age: $58 \pm 8$ years; range: $40-75$ years). The rationale of this approach relies on the assumption that occult micro-metastases may be present and that neoadjuvant chemotherapy is likely to improve the performance of a radical (R0) liver resection and that metastases initially deemed irresectable may be rendered operable for resection with curative intent.

\section{Patients' characteristics}

The relevant clinical data and tumour characteristics are shown in Table 1. Liver metastases were synchronous in 16 cases $(59 \%)$ and bilobar in four cases $(15 \%)$. The median maximal diameter of the metastases was $15 \mathrm{~mm}$ (range: 5-80 mm). Extrahepatic metastases were detected pre-operatively in three patients $(11 \%)$ with all extrahepatic sites being technically resectable either sequentially or at the time of the initial liver resection. The sites of the extrahepatic tumours were either lung (two cases) or the site of the original primary tumour resection (one case).

\section{Neoadjuvant chemotherapy}

The objectives in medical management were different according to the initial resectability of the metastases. For unresectable patients, chemotherapy was the only means to convert cases into a resectable state and was utilized for longer. For resectable patients, the first objective of the chemotherapy was to provide a time interval before surgery for assessment of the tumour biology, to treat potentially occult disease and to avoid surgery in those patients with rapidly progressive disease as a result of primary resistance to chemotherapy. A second objective in these resectable patients was to achieve cytoreduction both to limit the extent of liver resection and potentially post-operative morbidity as well as to facilitate a margin-free R0 liver resection. The median number of cycles of pre-operative chemotherapy per patient was eight (range: 212). In ten patients, systemic chemotherapy was continued post-operatively for a median of six cycles.

The response to chemotherapy was evaluated from serial imaging studies (thoraco- and abdomino-pelvic CT scan or MRI scanning of the abdomen where indicated) and was based on the change in tumour diameter according to the World Health Organisation criteria [23]. Response was defined as a $50 \%$ or more decrease in the total tumour size of lesions, with stabilization being defined as a less than $50 \%$ decrease or a less than $25 \%$ increase in the total tumour size. Progression was classified as a $25 \%$ or more increase in the total tumour size and/or the appearance of new lesions at any site. When more than one treatment regimen was used in the same patient, 
Table 1: Patients, tumour characteristics and pre-operative chemotherapy

\begin{tabular}{|c|c|}
\hline Characteristic & Value \\
\hline No. of patients & 27 \\
\hline Mean age & $58 \pm 9(40-75)$ \\
\hline Male/Female & $7 / 20$ \\
\hline \multicolumn{2}{|l|}{ Primary } \\
\hline Colon/rectum & $15 / 12$ \\
\hline Dukes C & $13(52 \%)$ \\
\hline \multicolumn{2}{|l|}{ Liver metastases at diagnosis } \\
\hline Synchronous & $16(59 \%)$ \\
\hline Bilobar & $4(15 \%)$ \\
\hline Single nodule & $20(74 \%)$ \\
\hline Median max size $(\mathrm{mm})$ & $15(5-80)$ \\
\hline \multicolumn{2}{|l|}{$1^{\text {st }}$ line therapy } \\
\hline Median no. courses & $8(2-12)$ \\
\hline FU-Fol-Raltitrexed & $4(15 \%)$ \\
\hline Oxaliplatin containing regimens & $20(74 \%)$ \\
\hline Irinotecan containing regimens & $3(11 \%)$ \\
\hline \multicolumn{2}{|l|}{$2^{\text {st }}$ line therapy } \\
\hline Median no. courses & $4(1-4)$ \\
\hline Oxaliplatin containing regimens & $1(50 \%)$ \\
\hline Irinotecan containing regimens & $1(50 \%)$ \\
\hline \multicolumn{2}{|l|}{ Chemotherapy after hepatectomy } \\
\hline Median no. courses & $4(1-8)$ \\
\hline FU-Fol & $1(20 \%)$ \\
\hline FU-Fol-Oxaliplatin & $5(80 \%)$ \\
\hline \multicolumn{2}{|c|}{ Tumour markers after preop. chemotherapy } \\
\hline Median preop. CEA (ng/mL) & $5.3(1-307)$ \\
\hline Median preop. CA 19.9 (UI/L) & $10.7(1-7138)$ \\
\hline
\end{tabular}

5FU: 5-fluorouracil; Fol: folinic acid 
the response to the last regimen used pre-operatively was considered for analysis.

\section{Selection for liver resection}

Patients were eligible for hepatic resection when the following conditions were met, namely: (1) no co-morbid conditions were present precluding liver resection, (2) all malignant liver disease was amenable to resection and ablative treatment whilst being able to retain at least $30 \%$ of non-tumoural liver parenchyma, (3) recurrence of the primary tumour was excluded and (4) either no non-resectable extrahepatic disease was detected by pre-operative serial imaging studies, or where potentially resectable extrahepatic tumour was detected, it was not considered a contraindication to sequential or synchronous surgery. The time interval between the final chemotherapy dose and hepatic surgery was usually $2-4$ weeks to minimize the risk of tumour progression and to reduce perioperative morbidity. This approach was adopted in accordance with other similar reports $[24,25]$. The policy of liver resection attempted a radical resection either by anatomic or non-anatomic (wedge) resection, sparing the largest amount of liver parenchyma possible but providing a tumour-free margin of $1 \mathrm{~cm}$ whenever feasible. All procedures routinely used intra-operative ultrasound (IOUS), an ultrasonic dissector for parenchymal transection (CUSA) and a combination of the argon beam and bipolar coagulation forceps to reduce intra-operative blood loss. The radio-frequency ablation device (TARF) was used in combination with conventional surgery to treat non-resectable remnant lesions, thus permitting an extension of the indications for liver resection in patients who otherwise would not have been candidates for surgery.

\section{Post-operative follow-up}

Patients were followed up one month after surgery and then every four months thereafter with evaluation of tumour markers (CEA, and CA 19-9 serum levels), liver function tests and by hepatic ultrasound. An abdomino-pelvic or thoraco-abdominal CT scan was performed every six months during the follow-up. In the case of resectable extrahepatic metastasis(es), sites were resected 203 months following definitive hepatic surgery, using systemic chemotherapy between operations in order to prevent tumour progression.

\section{Analysis of the data}

Overall and disease-free survival probabilities were determined by the Kaplan-Meier analysis [26] and compared using the log- rank test [27]. A multivariate analysis using a Cox model was performed to determine independent prognostic factors for survival, with $p$ values $<0.05$ being considered significant.

\section{Results}

Liver resection was performed following an objective tumour response in ten patients (37\%), after stabilization in a further ten patients (37\%) and after tumour progression in seven patients (26\%). Major liver resections ( $\geq 2$ segments). were all performed with curative intent and included two right hepatectomies, one left hepatectomy, one extended right hepatectomy, four bisegmentectomies, two bisegmentectomies plus one segmetectomy and two bisegmentectomies plus a wedge resection. For two patients $(3 \%)$, liver resection was combined with a gastrointestinal resection (namely an anterior resection of the rectum). Perioperative mortality was nil (30 days following surgery). Eighteen patients (67\%) were discharged without complications with one patient (3\%) undergoing a right hepatectomy having mild post-operative reversible liver failure. Among the minor complications in nine patients $(33 \%)$, there were three pleural effusions, two abdominal collections, two wound infections and two central venous catheter (CVC) infections. All patients underwent hepatic resections with curative intent (R0 resections) with no evidence of microscopic involvement of the surgical margin. The patient and tumour characteristics according to response to preoperative chemotherapy regimens utilized are shown in Table 2.

\section{Outcome}

Following a mean follow-up of 36 months (range: 8-110 months), 18 patients suffered from recurrence (67\%) amongst the 27 patients. Liver recurrence was isolated in eight patients $(30 \%)$ and associated with extrahepatic recurrence in four cases $(15 \%)$. Of the 12 patients with hepatic recurrence, two underwent a repeat hepatectomy. Of the 25 patients initially free of extrahepatic disease, ten subsequently developed extrahepatic recurrences $(37 \%)$. Of these latter four patients underwent one or more re-operations for extrahepatic recurrence.

\section{Survival}

The overall survival (OS) of the 27 patients was $93 \%, 57 \%$ and $34 \%$ at one, three and five years, respectively, with a median survival of 30 months (Figure 1). At last follow-up, 12 patients 
Table 2: Patient and tumour characteristics according to response to pre-operative chemotherapy

\begin{tabular}{|c|c|c|c|}
\hline & Response & $\begin{array}{l}\text { Stabilization or } \\
\text { progression }\end{array}$ & $p$ \\
\hline No. of patients & $10(37 \%)$ & $17(63 \%)$ & \\
\hline Mean age & $57 \pm 8$ & $58 \pm 9$ & 0.63 \\
\hline Male & $3(30 \%)$ & $4(23 \%)$ & 0.71 \\
\hline \multicolumn{4}{|l|}{ Primary } \\
\hline Rectum & $3(30 \%)$ & $4(23 \%)$ & 0.25 \\
\hline Dukes C & $9(90 \%)$ & $14(82 \%)$ & 0.18 \\
\hline \multicolumn{4}{|l|}{ Liver metastases at diagnosis } \\
\hline Synchronous & $5(50 \%)$ & $11(65 \%)$ & 0.45 \\
\hline Multiple nodules & $4(40 \%)$ & $3(17 \%)$ & 0.20 \\
\hline Mean max size $(\mathrm{mm})$ & $22 \pm 14$ & $21 \pm 26$ & 0.94 \\
\hline \multicolumn{4}{|l|}{ Pre-operative chemotherapy } \\
\hline \multicolumn{4}{|l|}{$1^{\text {st }}$ line therapy } \\
\hline Median no. courses & $6.3 \pm 1.4$ & $6.5 \pm 2.5$ & 0.42 \\
\hline Fu-Fol-Raltitrexed & $2(50 \%)$ & $2(50 \%)$ & \\
\hline Oxaliplatin containing regimens & $8(40 \%)$ & $12(60 \%)$ & \\
\hline Irinotecan containing regimens & 0 & $3(100 \%)$ & \\
\hline \multicolumn{4}{|l|}{ Tumour markers after preop. } \\
\hline chemotherapy & $21 \pm 49$ & $56 \pm 88$ & 0.26 \\
\hline Median preop. CEA (ng/mL) & $11 \pm 14$ & $642 \pm 1852$ & 0.30 \\
\hline Median preop. CA 19.9 (UI/L) & & & \\
\hline
\end{tabular}

5FU: 5-fluorouracil; Fol: folinic acid

(44\%) had died with disease. Of the 15 patients alive, nine $(33 \%)$ were disease-free and six $(22 \%)$ were alive with disease (two cases of hepatic disease, two with extrahepatic disease and two with both sites involved). Univariate analysis was performed with survival as an end point for all items concerning patient characteristics, data pertaining to the primary tumour (location, stage lymph node invasion, adjuvant chemotherapy, time interval between colectomy and hepatectomy), preoperative chemotherapy (number of courses, number of lines of chemotherapy, utilization of chronomodulated therapy, type of regimen, response to chemotherapy), liver metastases (synchronous, bilobar versus unilobar, number, size, respectability, serum CEA and serum CA 19-9, metastatic pedicle lymph nodes), concomitant extrahepatic disease (location, curative resection) and technique of liver resection (utilization of portal embolization, two-stage versus synchronous procedures, combined radio-frequency ablation, major hepatectomy, anatomic versus non-anatomic resection, curative versus non-curative resection, number and size of metastases in the specimen, blood units transfused and duration of hospital stay). In some of these subgroups, there were very small numbers for adequate comparison.

On univariate analysis, the only significant factor positively predicting survival was the response to neoadjuvant chemotherapy $(64 \%$ versus $15 \%$ five-year survival for responder versus non-responders respectively, $p=0.044)$. This effect is shown graphically in Figure 2. The response to 


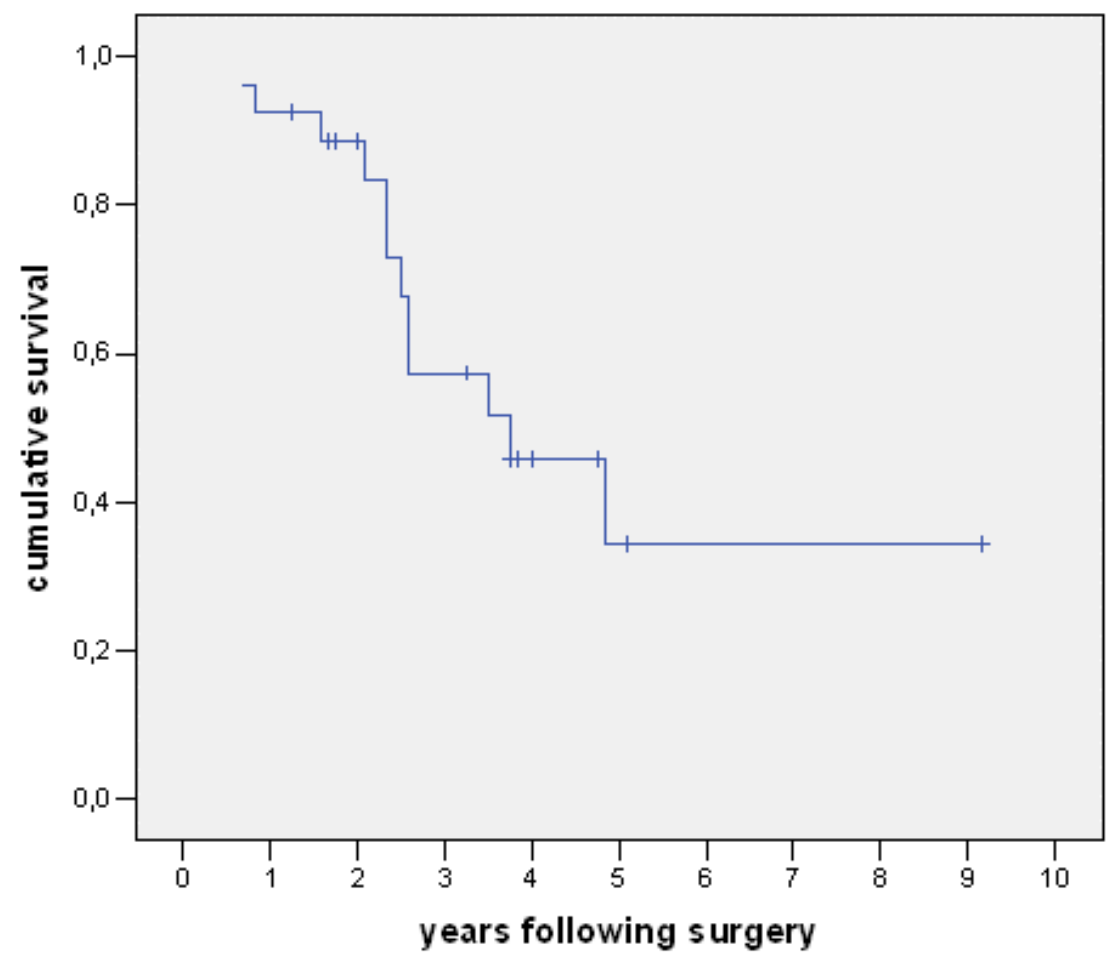

$\mathrm{N}^{\circ}$ of patients at risk

$\begin{array}{lllllllllll}27 & 24 & 17 & 11 & 5 & 3 & 1 & 1 & 1 & 1 & 0\end{array}$

Figure 1: Survival of 27 patients undergoing liver resection following neoadjuvant chemotherapy for colorectal-cancer liver metastases.

neoadjuvant chemotherapy, the number of metastases and the total size of metastases, was matched in a multivariate analysis where the response to pre-operative chemotherapy was confirmed as the only significant prognostic variable affecting survival (HR 4.531; I.C. 1.002-21.204, $p=0.05)$.

\section{Discussion}

This small study shows that liver resection combined with preand post-operative (sandwich) chemotherapy offers the possibility of long-term survival of patients with chemoresponsive liver metastases (single/multiple and/or initially irresectable) from colorectal cancer. This benefit can be obtained only when the disease confined to the liver is controlled by chemotherapy prior to completely resectional surgery. Tumour progression whilst on pre-operative chemotherapy is associated with a poor outcome, even when hepatectomy is performed with curative intent.

This neoadjuvant approach has been reported to be associated with prolonged OS by others where it has been used for potentially resectable liver lesions, with demonstration of progression-free survival advantage over unresected cases [28]. It is, however, recognized that the global impact of sandwich pre- and post-operative chemotherapy on such progression-free survival is relatively low where, as found in our study, less than half of the cases resected are disease-free at five years [29]. Our approach does, however, appear safe with an acceptable morbidity, which is not exacerbated by the use of adjuvant chemotherapy [15,17] although post-operative hepatotoxicity is somewhat dependent upon the number of cycles administered rather than on the type of chemotherapy used [25]. Data concerning the hepatotoxicity of systemic neoadjuvant chemotherapy are, however, scarce [21] and may 


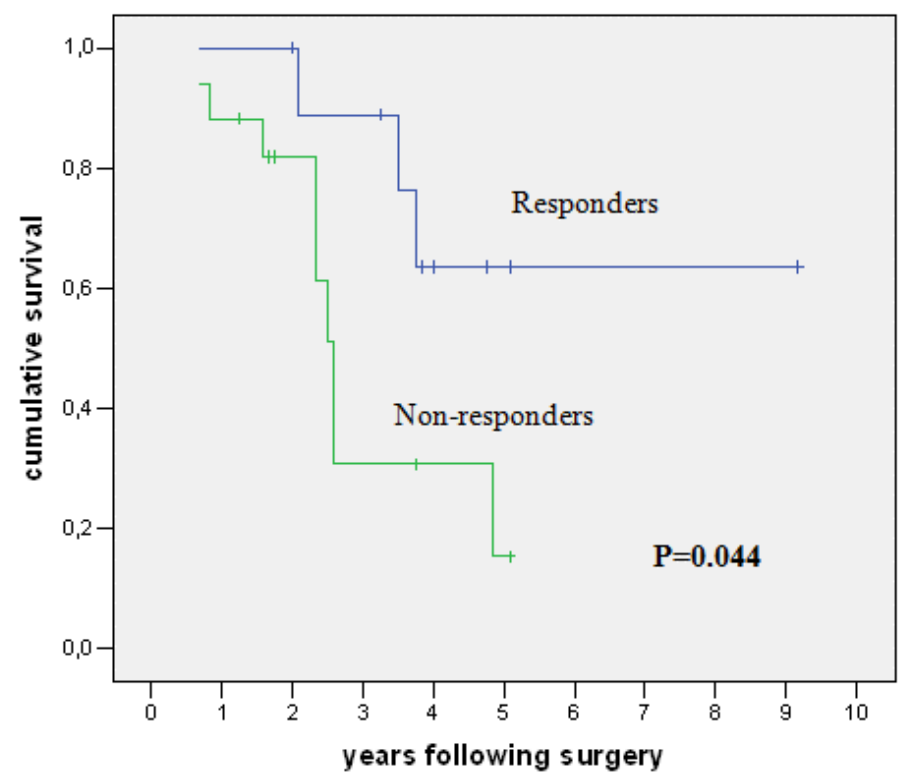

$\begin{array}{llllllllllll}\text { Responders } & 10 & 9 & 9 & 8 & 3 & 2 & 1 & 1 & 1 & 1 & 0\end{array}$

$\begin{array}{llllllllllll}\text { Non-resp. } & 17 & 15 & 8 & 3 & 2 & 1 & 0 & 0 & 0 & 0 & 0\end{array}$

Figure 2: Survival of neoadjuvant chemotherapy patients—responders versus non-responders.

suggest a role in selected cases for interstitial concomitant therapies [30].

Available data would suggest that initial perioperative morbidity following hepatic resection appears to adversely affect the longer-term cancer-specific survival [31] but that medium-term health-related quality of life assessment after hepatectomy justifies such an aggressive approach [32]. There is no uniform policy regarding the role of synchronous over-staged hepatectomy in this setting. It would appear that although synchronous metastasis resection is safe and has oncologic merit, $[33,34]$ the potential benefit of the neoadjuvant approach is to define tumour biology where initial chemo-responsiveness selects those cases suitable for metastasis excision. This may be particularly evident when the primary tumour is more advanced, where overall cancer-specific prognosis is adversely affected when $>4$ paracolic lymph nodes are involved [13].

It should be recognized that complete chemo-responsiveness on imaging may frequently be associated both with macroscopic and microscopic evidence of residual disease that may account for the relatively high incidence of hepatic in-situ recurrence found in our study as well as by others [35]. Tumour progression on chemotherapy is uniformly associated with a poor prognosis [36,37], as reported by Adam and colleagues, and similar to our study, this was found even when a potentially curative R0 hepatectomy was performed [38]. This group also noted (unlike our study) that the prognosis of radical hepatectomy after neoadjuvant therapy was affected by the number of metastases and the pre-operative serum level of CA $19-9$, but similar to our findings, that the type of chemotherapy was not significant to the outcome provided that there was a therapeutic response. As in our study, others have reported that the presence of some types of extrahepatic disease does not contraindicate hepatectomy or subsequent excision of resectable extrahepatic sites in selected cases [39]. Where recurrence is restricted to the liver, as occurred in our study in one-third of recurrent cases, this may be amenable to repeat hepatic resection [40]. Outcome in this circumstance is dependent upon the radicality of re-resection in much the same way that it is in the initial resection.

In this study, the number of nodules was not a contraindication to resectional surgery. The five-year survival following such R0 
liver resection was $34 \%$ in our cases: data that compare favourably with other surgical series reporting three-year and five-year survival of $21 \%$ [41] and $23 \%$, respectively [33, 42]. One question that remains is whether the response to chemotherapy in our cases simply identifies patients who have a pre-determined favourable prognosis or whether the response is able to modify the actual course of the disease. Supporting the latter hypothesis, progression was clearly identified as an independent adverse prognostic factor of outcome on multivariate analysis. Moreover, treating resectable patients with neoadjuvant chemotherapy did not lead to non-resectable metastases during the course of the study: an effect also observed by others [29, 38]. This effect, combined with longterm survival in some cases initially defined as non-resectable which became down-staged by the neoadjuvant approach permitting complete resections, argues for the possibility that the course of the disease could be altered by such an aggressive strategy [24, 43, 44].

In conclusion, the response to neoadjuvant chemotherapy plays a key role in the potential benefit offered by radical liver resection in selected patients with hepatic metastatic disease from colorectal cancer. The poor results obtained by surgery in patients with tumour progression suggest that control of the disease with a modern combination regimen is preferable to immediate surgery. This delayed approach awaiting initial chemo-responsiveness might also prove to be relatively liver sparing and better defines those patients who are potentially advantaged by a formal hepatic resection as opposed to a tailored segmentectomy. Moreover, in those cases where larger metastases completely respond in one area of the liver, resection of the contralateral lobe may become an operative option [35]. This view is corroborated by recent evidence to show that the prognosis is adversely affected in those patients undergoing synchronous resection of hepatic metastatic disease with their primary tumour when the primary is extensive (T4), when it is infiltrating adjacent structures and when there are multiple hepatic metastases [45].

Overall, the data concerning neoadjuvant benefit to radical hepatectomy in colorectal hepatic metastatic disease are hard to interpret. This is as a result of variable histopathology in the liver, differing chemotherapy schedules, varying types of liver resections and different ischaemia/reperfusion cycling techniques during hepatic parenchymal transection. In this setting, it is not surprising that patients with multiple metastases tend to have more prolonged chemotherapy exposure, more extended resections and larger tumour/remnant liver ratios. Resections for hepatic colorectal metastases are increasing in incidence [46] and it is expected that the approach towards neoadjuvant therapy even for resectable hepatic metastases will be modified in the future by the concomitant use of antiangiogenic therapy [47] followed by an aggressive approach. 


\section{References}

1. Steele G Jr and Ravikumar TS (1989) Resection of hepatic metastases from colorectal cancer: biologic perspective Ann Surg 210 127-38 PMID 2667471 doi:10.1097/00000658-198908000-00001

2. Scheele J (1993) Hepatectomy for liver metastases $\mathrm{Br} \mathrm{J}$ Surg $80 \quad 3 \quad 274-6$ PMID 8472130 doi:10.1002/bjs. 1800800302

3. Adson MA, van Heerden JA, Adson MH, Wagner JS and Ilstrup DM (1984) Resection of hepatic metastases from colorectal cancer Arch Surg 1196 647-51 PMID 6732473

4. Nordlinger B, Jaeck D, Guiguet M et al (1992) Surgical resection of hepatic metastases: multicentric retrospective study by the French Association of Surgery Treatment of Hepatic Metastases of Colorectal Cancer, ed B Nordlinger, D Jaeck (Paris: Springer-Verlag) pp129-46

5. Scheele J, Stang R, Altendorf-Hofmann A and Paul M (1995) Resection of colorectal liver metastases World J Surg 191 59-71 PMID 7740812 doi:10.1007/BF00316981

6. Fong $Y$ and Blumgart LH (1998) Hepatic colorectal metastasis: current status of surgical therapy. Oncology (Williston Park) 1210 1489-98 PMID 9798202

7. Tamandl D, Gruenberger B, Herberger B, Schoppmann S, Bodingbauer M, Schindl M et al (2007) Selective resection of colorectal liver metastases Eur J Surg Oncol 332 174-82 Epub 2006 PMID 17046194 doi:10.1016/j.ejso. $\underline{2006.09 .008}$

8. Bengtsson $G$, Carlsson $G$, Hafstrom $L$ and Johnson PE (1981) Natural history of patients with untreated liver metastases from colorectal cancer Am J Surg 1415 586-9 PMID 7223955 doi:10.1016/0002-9610(81)90057-X

9. Scheithauer W, Rosen H, Kornek GV, Sebesta C and Depisch D (1993) Randomised comparison of combination chemotherapy plus supportive care with supportive care alone in patients with metaststic colorectal cancer BMJ 3066880 752-5 PMID 7683942 doi:10.1136/bmj.306.6880.752

10. Stangl R, Altendorf-Hofmann A, Charnley RM and Scheele $J$ (1994) Factors influencing the natural history of colorectal liver metastases Lancet 3438910 1405-10 PMID 7515134 doi:10.1016/S0140-6736(94)92529-1

11. Hobday TJ, Kugler JW, Mahoney MR, Sargent DJ, Sloan JA, Fitch TR et al (2002) Efficacy and quality-of-life data are related in a phase II trial of oral chemotherapy in previously untreated patients with metastatic colorectal carcinoma $\mathrm{J}$ Clin Oncol 20 4574-80 PMID $\underline{12454115}$ doi: $10.1200 / \mathrm{JCO} .2002 .08 .535$
12. Lambert LA, Colacchio TA and Barth RJ Jr (2000) Interval hepatic resection of colorectal metastases improves patient selection Arch Surg 1354 473-9 PMID 10768715 doi:10.1001/archsurg.135.4.473

13. Minagawa M, Yamamoto J, Miwa S, Sakamoto $\mathrm{Y}$, Kokudo N, Kosuge T, Miyagawa S and Makuuchi M (2006) Selection criteria for simultaneous resection in patients with synchronous liver metatsasis Arch Surg 14110 1006-12 PMID 17043279 doi:10.1001/archsurg.141.10. $\underline{1006}$

14. Leonard GD, Brenner B and Kemeny NE (2005) Neoadjuvant chemotherapy before liver resection for patients with unresectable liver metastases from colorectal carcinoma J Clin Oncol 239 2038-48 PMID 15774795 doi:10.1200/JCO.2005.00.349

15. Hewes JC, Dighe $S$, Morris RW, Hutchins RR, Bhattacharya S and Davidson BR (2007) Preoperative chemotherapy and the outcome of liver resection for colorectal metastases World J Surg 312 353-64 PMID 17219289 doi:10.1007/s00268-006-0103-8

16. King PD and Perry MC (2001) Hepatoxicity of chemotherapy Oncologist 62 162-76 PMID 11306728 doi:10.1634/theoncologist.6-2-162

17. Zorzi D, Laurent A, Pawlik TM, Lauwers GY, Vauthey JN and Abdalla EK (2007) Chemotherapy-associated hepatotoxicity and surgery for colorectal liver metastases $\mathrm{Br} J$ Surg $94 \quad 3 \quad 274-86$ PMID 17315288 doi: $10.1002 /$ bjs. 5719

18. Elias $D$, Lasser $P$, Rougier $P$, Ducreux $M$, Bognel $C$ and Roche A (1995) Frequency, technical aspects, results, and indications of major hepatectomy after prolonged intra-arterial hepatic chemotherapy for initially unresectable hepatic tumours J Am Coll Surg 1802 213-9 PMID 7850058

19. Parc $Y$, Dugue L, Farges $O$, Hiramatsu K, Sauvanet $A$ and Belghiti J (2000) Preoperative systemic 5-fluorouracil does not increase the risk of liver resection Hepatogastroenterology 4736 1703-5 PMID 11149036

20. Shankar A, Leonard P, Renaut AJ, Lederman J, Lees WR, Gillams AR, Harrison E and Taylor I (2001) Neo-adjuvant therapy improves resectability rates for colorectal liver metastases Ann $R$ Coll Surg Engl 8322 85-8 PMID 11320935

21. Pocard $M$, Vincent-Salomon $A$, Girodet $J$ and Salmon RJ (2001) Effects of preoperative chemotherapy on liver function tests after hepatectomy Hepatogastroenterology 4841 1406-8 PMID 11677975

22. Tanaka K, Adam R, Shimada H, Azoulay D, Levi F and Bismuth H (2003) Role of neoadjuvant chemotherapy in the treatment of multiple colorectal metastases to the 
liver Br J Surg 908 963-9 PMID 12905549 doi:10.1002/ bjs. 4160

23. World Health Organization (1979) Handbook for reporting results of cancer treatment WHO Offset Publication No. 48 (Geneva: World Health Organization)

24. Adam R, Delvart V, Pascal G, Valeanu A, Castaing D, Azoulay $D$ et al (2004) Rescue surgery for unresectable colorectal liver metastases downstaged by chemotherapy: a model to predict long-term survival Ann Surg 2404 644-57 PMID 15383792

25. Karoui M, Penna C, Amin-Hashem M, Mitry E, Benoist S, Franc B, Rougier P and Nordlinger B (2006) Influence of preoperative chemotherapy on the risk of major hepatectomy for colorectal liver metastases Ann Surg $243 \quad 1 \quad 1-7 \quad$ PMID 16371728 doi:10.1097/01.sla. 0000193603.26265.c3

26. Kaplan EL and Meier P (1958) Nonparametric estimation from incomplete observation J Am Stat Assoc 53 457-81 doi:10.2307/2281868

27. Peto $R$ and Pike MC (1973) Conservation of the approximation (O-E2)/E in the log-rank test for survival data on tumour incidence data Biometrics 293 579-84 PMID 4793138 doi: $10.2307 / 2529177$

28. Sperti E, Faggiuolo R, Gerbino A, Magnino A, Muratore A, Ortega C, Ferraris R, Leone F, Capussotti L and Aglietta M (2006) Outcome of metastatic colorectal cancer: analysis of a consecutive series of 229 patients. The impact of a multidisciplinary approach Dis Colon Rectum 4910 1596-601 PMID 16988853 doi:10.1007I $\underline{\mathrm{s} 10350-006-0662-7}$

29. Allen PJ, Kemeny N, Janargin W, DeMatteo R, Blumgart L and Fong $Y$ (2003) Importance of response to neoadjuvant chemotherapy in patients undergoing resection of synchronous colorectal liver metastases $\mathrm{J}$ Gastrointest Surg 71 109-17 PMID 12559192 doi:10.1016/ S1091-255X(02)00121-X

30. Meric F, Patt YZ, Curley SA, Chase J, Roh MS, Vauthey JN and Ellis LM (2000) Surgery after downstaging of unresectable hepatic tumors with intra-arterial chemotherapy Ann Surg Oncol 77 490-5 PMID 10947016 doi:10.1007/s10434-000-0490-2

31. Laurent C, Sa Cunha A, Couderc P, Rullier E and Saric J (2003) Influence of postoperative morbidity on longterm survival following liver resection for colorectal metastases $\mathrm{Br} J$ Surg 909 1131-6 PMID 12945082 doi:10.1002/bjs.4202

32. Langenhoff BS, Krabbe PF, Peerenboom L, Wobbes T and Ruers TJ (2006) Quality of life after surgical treatment of colorectal liver metastases Br J Surg 938 1007-14 PMID 16739102 doi:10.1002/bjs.5387
33. Weber SM, Jarnagin WR, DeMatteo RP, Blumgart LH and Fong $Y(2000)$ Survival after resection of multiple hepatic colorectal metastases Ann Surg Oncol 79643 50 PMID 11034240 doi:10.1007/s10434-000-0643-3

34. Tsai MS, Su YH, Ho MC, Liang JT, Chen TP, Lai HS and Lee PH (2007) Clinicopathological features and prognosis in respectable synchronous and metachronous colorectal liver metastasis Ann Surg Oncol 14 786-94 PMID 17103254 doi:10.1245/s10434$\underline{006-9215-5}$

35. Benoist S, Brouquet A, Penna C, Julie C, El Hajjam M, Chagnon S, Mitry E, Rougier P and Nordlinger B (2006) Complete response of colorectal liver metastases after chemotherapy: does it mean cure? J Clin Oncol 2424 3939-45 PMID 16921046 doi:10.1200/JCO.2006.05.8727

36. Therasse P, Arbuck SG, Eisenhauer EA, Wanders J, Kaplan RS, Rubinstein L et al (2000) New guidelines to evaluate the response to treatment in solid tumors $\mathrm{J}$ Natl Cancer Inst 923 205-16 PMID 10655437 doi: 10.1093/jnci/92.3.205

37. Trillet-Lenoir $\mathrm{V}$, Freyer $\mathrm{G}$, Kaemmerlen $\mathrm{P}$, Fond A, Pellet $\mathrm{O}$, Lombard-Bohas C et al (2002) Assessment of tumour response to chemotherapy for metastatic colorectal cancer. Accuracy of the RECIST criteria $\mathrm{Br} J$ Radiol 75 899 903-8 PMID 12466256

38. Adam R, Pascal G, Castaing D, Azoulay D, Delvart V, Paule B, Levi F and Bismuth $\mathrm{H}$ (2004) Tumor progression while on chemotherapy: a contraindication to liver resection for multiple colorectal metastases? Ann Surg 2406 1052-64 PMID 15570210 doi:10.1097/01.sla. $\underline{0000145964.08365 .01}$

39. Elias D, Ouellet JF, Bellon N, Pignon JP, Pocard M and Lasser P (2003) Extrahepatic disease does not contraindicate hepatectomy for colorectal liver metastases $\mathrm{Br} J$ Surg 905 567-74 PMID 12734864 doi:10.1002/bjs.4071

40. Thelen A, Jonas S, Benckert C, Schumacher G, LopezHanninen E, Rudolph B, Neumann $U$ and Neuhaus $P$ (2006) Repeat liver resection for recurrent liver metastases from colorectal cancer Eur J Surg Oncol 33 3 324-8 PMID 17112697 doi:10.1016/i.ejso.2006.10.016

41. Capussotti L, Muratore A, Mulas MM, Massucco $P$ and Aglietta M (2006) Neoadjuvant chemotherapy and resection for initially irresectable colorectal liver metastsases $\mathrm{Br} J$ Surg 938 1001-6 PMID 16739103 doi:10.1002/bjs.5386

42. Figueras J, Valls $\mathrm{C}$, Rafecas $\mathrm{A}$, Fabregat $\mathrm{J}$, Ramos $\mathrm{E}$ and Jaurrieta E (2001) Resection rate and effect of chemotherapy on survival after surgery for colorectal liver metastases $\mathrm{Br} J$ Surg 887 980-5 PMID 11442531 doi:10.1046/j.0007-1323.2001.01821.x 
43. Bismuth $H$, Adam R, Levi F, Farabos C, Waechter F, Castaing D, Majno P and Engerran L (1996) Resection of nonresectable liver metastases from colorectal cancer after neoadjuvant chemotherapy Ann Surg 2244 509-22 $\underline{\text { PMID } 8857855}$ doi:10.1097/00000658-199610000-00009

44. Adam R, Avisar E, Ariche A et al (2001) Five-year survival following hepatic resection after neoadjuvant therapy for nonresectable colorectal liver metastses Ann Surg Oncol 84 347-53 PMID 11352309 doi:10.1007/s10434$\underline{001-0347-3}$

45. Capussotti L, Vigano L, Ferrero A, Lo Tesoriere R, Ribero $D$ and Polastri R (2007) Timing of resection of liver metastases synchronous to colorectal tumor: proposal of prognosis-based decisional model. Ann Surg Oncol 14 1143-50 PMID 17200913 doi:10.1245/s10434-0069284-5

46. Khatri VP, Petrelli NJ and Belghiti J (2005) Extending the frontiers of surgical therapy for hepatic colorectal metastases: is there a limit? J Clin Oncol 2333 8490-9 PMID 16230676 doi:10.1200/JCO.2004.00.6155

47. Yoo PS, Lopez-Soler RI, Longo WE and Cha CH (2006) Liver resection for metastatic colorectal cancer in the age of neoadjuvant chemotherapy and bevacizumab Clin Colorectal Cancer 63 202-7 PMID 17026789 doi: 10.3816/CCC.2006.n.036 